\title{
ANALISIS TINGKAT KEPUASAN DAN KEPENTINGAN PENGGUNA APLIKASI SAKTI DENGAN PIECES FRAMEWORK
}

Heru Pudyo Nugroho

Direktorat Jenderal Perbendaharaan

Jamila Lestyowati

Badan Pendidikan dan Pelatihan Keuangan

Alamat Korespondensi: pudyonugroho@gmail.com dan jlestyowati@kemenkeu.go.id

\section{ABSTRACT}

This study aims to analyze the level of satisfaction and importance of Sistem Aplikasi Keuangan Tingkat Instansi (SAKTI) users, the strengths and weaknesses of SAKTI, and the components that need to be improved. The study used descriptive quantitative methods with primary data from 45 respondents. They are SAKTI users from the piloting office units in regional offices of DJP in Central Java and Yogyakarta. The data analysis method is the Importance Performance Analysis (IPA) method in the evaluation of SAKTI information systems with PIECES framework consisting of six attributes, namely Performance, Information, Economy, Control, Efficiency, and Service. The results showed that all PIECES variables of level of importance are very important. All PIECES attributes have a negative gap value. It means that the satisfaction value is below their expectations. Based on the IPA analysis, it was found that there were 12 PIECES items in quadrant A as the main priority for improvement.

\section{KATA KUNCI:}

PIECES framework, analisis IPA, kepuasan dan kepentingan pengguna, SAKTI

\begin{abstract}
ABSTRAK
Penelitian ini bertujuan untuk menganalisis tingkat kepuasan dan kepentingan pengguna Sistem Aplikasi Keuangan Tingkat Instansi (SAKTI), kekuatan, dan kelemahan SAKTI, serta menganalisis komponen yang perlu ditingkatkan kualitasnya. Penelitian menggunakan metode kuantitatif deskriptif dengan data primer berasal dari 45 responden pengguna SAKTI dari satker piloting di DJP wilayah Jawa Tengah dan DIY. Analisis data dengan metode Importance Performance Analysis (IPA) pada evaluasi sistem informasi SAKTI dengan PIECES framework yang terdiri dari enam atribut yaitu Performance, Information, Economy, Control, Eficiency, dan Service. Hasil penelitian menunjukkan bahwa semua variabel PIECES tingkat kepentingan/harapan adalah sangat penting, semua atribut PIECES memiliki nilai gap negatif artinya nilai kepuasan ada di bawah harapan mereka. Berdasarkan analisis IPA diperoleh hasil bahwa ada 12 butir PIECES terdapat di kuadran A sebagai prioritas utama untuk diperbaiki.
\end{abstract}

\section{KLASIFIKASI JEL:}

M150

\section{CARA MENGUTIP:}

Nugroho, H. P., \& Lestyowati, J. (2020). Analisis tingkat kepuasan dan kepentingan pengguna aplikasi sakti dengan pieces framework. Indonesian Treasury Review: Jurnal Perbendaharaan, Keuangan Negara dan Kebijakan Publik, 5(2), 93-104. 


\section{PENDAHULUAN}

\subsection{Latar Belakang}

Era informasi 4.0 ditandai dengan tantangan persaingan pasar, dengan perubahan yang cepat, kompleks, global, sangat kompetitif, dan terfokus pada pelanggan. Lebih jauh lagi, faktor-faktor ini bisa berubah secara cepat dan tidak terduga (Knoke dalam Suyanto, 2005, hal. 3). Penggabungan antara teknologi komputer dan telekomunikasi telah menghasilkan suatu revolusi di bidang sistem informasi (Simarmata, 2006, hal. 7). Implementasi Teknologi Informasi dan Komunikasi (TIK) menjadi suatu keharusan bagi entitas swasta maupun entitas pemerintah agar dapat survive dan optimal dalam memenuhi kebutuhan pelanggan ataupun masyarakat pengguna layanan.

Kementerian Keuangan sebagai entitas publik yang melaksanakan fungsi pengelolaan keuangan negara telah melakukan modernisasi dengan implementasi TIK diantaranya melalui pembangunan berbagai aplikasi untuk pengelolaan keuangan satuan kerja. Aplikasi ini digunakan untuk tahap perencanaan, pelaksanaan maupun pertanggungjawaban anggaran, misalnya aplikasi persediaan, aset tetap (SIMAK BMN), RKA-KL DIPA, aplikasi SPM, SILABI, dan SAIBA.

Kebutuhan untuk terus mengembangkan sistem informasi terintegrasi yang lebih user frendly mendorong upaya memadukan berbagai aplikasi yang digunakan oleh satuan kerja agar lebih simple dan efisien. Konsep better, cheaper, faster, dan akuntabel juga harus diterapkan dalam pengelolaan keuangan pemerintahan. Seiring penerapan aplikasi Sistem Perbendaharaan dan Anggaran Negara (SPAN) secara penuh pada awal tahun 2015 yang merupakan modernisasi pelaksanaan fungsi pengelolaan keuangan negara pada Bendahara Umum Negara, maka aplikasi SAKTI sebagai wujud modernisasi pengelolaan anggaran pada Pengguna Anggaran Kementerian/Lembaga (K/L) yang terintegrasi dengan SPAN mulai diterapkan pula melalui PMK nomor 223/PMK.05/2015 yang menjadi dasar penerapan secara bertahap. Aplikasi terintegrasi ini mengambil peran besar untuk menggantikan aplikasi-aplikasi lain yang sebelumnya digunakan satker dalam perencanaan, pelaksanaan, dan pertanggungjawaban keuangannya.

Sebagaimana Mukhtaromin (2018, hal. 588) meneliti penerapan SAKTI pada Badan Pendidikan dan Pelatihan Keuangan (BPPK), pengamatan yang penulis lakukan pada satuan kerja Kementerian Keuangan yang telah menerapkan SAKTI, terdapat berbagai permasalahan yang muncul pada fase piloting implementasi SAKTI. Permasalahan terutama adalah kemampuan Sumber Daya Manusia (SDM), resistensi petugas satker terhadap perubahan mendasar pada aplikasi satker, ketersediaan perangkat Information Technology (IT) pendukung yang memadai, keandalan aplikasi itu sendiri maupun interaksi dengan petugas Ditjen Perbendaharaan (DJPb) sebagai host SAKTI. Sebagai unit Eselon I Kementerian Keuangan (Kemenkeu) dengan jumlah satker terbanyak, Satker Ditjen Pajak (DJP) dimasukkan pada tahap piloting tahun ketiga dari satker Kemenkeu. Penelitian ini dilakukan dengan melakukan analisis tingkat kepuasan dan kepentingan pengguna SAKTI pada satker DJP di wilayah Jawa Tengah (Jateng) dan Daerah Istimewa Yogyakarta (DIY) yang merupakan satker Kemenkeu terbanyak di wilayah Jateng dan DIY sehingga dapat mewakili persepsi satker DJP. Kepuasan pengguna menjadi salah satu tolak ukur menentukan sistem informasi berhasil atau tidak (DeLone \& McLean, 1992, hal. 62) sehingga untuk dapat meningkatkan kepuasan pelanggan perlu pengukuran tingkat kepuasan pelanggan dengan membandingkan persepsi pelanggan dengan harapan pelanggan mengenai kinerja SAKTI.

\subsection{Rumusan Masalah}

Berdasarkan latar belakang di atas, maka rumusan masalah pada penelitian ini adalah sebagai berikut: (1) Bagaimana tingkat kepuasan dan kepentingan pengguna aplikasi SAKTI pada satker piloting DJP Kementerian Keuangan di Jateng dan DIY? (2) Bagaimana harapan pengguna terhadap aplikasi SAKTI berdasarkan persepsi kepentingan dan kepuasan pengguna?

\subsection{Tujuan Penelitian}

Tujuan penelitian ini adalah menganalisis tingkat kepuasan dan kepentingan pengguna SAKTI, mengetahui kekuatan dan kelemahan SAKTI, sehingga dapat memaksimalkan kepuasan pengguna/stakeholder dalam mengelola keuangan satkernya.

\section{LANDASAN TEORI}

\subsection{Siklus Keuangan Satker}

Satuan kerja mengelola keuangan melalui dokumen anggaran yaitu DIPA. Setiap satker akan melalui siklus anggaran/keuangan di satkernya. Siklus tersebut dimulai dari tahap perencanaan dan penganggaran, pelaksanaan, dan pertangungjawaban anggaran.

Penetapan pejabat pengelola perbendaharaan ditetapkan untuk dapat mengelola keuangan. Menteri/Pimpinan Lembaga sebagai Pengguna Anggaran. Pada lingkup satker terdapat pejabat pengelola perbendaharaan yang terdiri dari Kuasa Pengguna Anggaran (KPA), Pejabat Pembuat 
Komitmen (PPK), Pejabat Penandatangan Surat Perintah Membayar (PPSPM), pejabat pengadaan, bendahara pengeluaran, bendahara penerimaan, pejabat pengelola belanja pegawai, dan pejabat lain yang diperlukan untuk melaksanakan perbendaharaan satker. Setiap pejabat memiliki kewenangan dan tugas yang berbeda-beda.

Tahapan perencanaan dan penganggaran diimplementasikan dengan disusunnya dokumen Rencana Kerja dan Anggaran-Kementerian dan Lembaga (RKA-KL) sebagai dokumen penganggaran yang berisi program dan kegiatan suatu K/L yang merupakan penjabaran dari Rencana Kerja Kementerian/Lembaga dan Rencana Kerja Pemerintah. Di dalamnya berisi alokasi anggaran yang diperlukan untuk melaksanakan kegiatan dan program pada tahun yang direncanakan.

Pada tahap pelaksanaan anggaran, pejabat perbendaharaan yang terlibat adalah KPA, PPK, PPSPM, pejabat pengadaan, bendahara pengeluaran, dan pelaksana kegiatan. Pada tahap ini satker melakukan kegiatan sesuai dengan tugas dan fungsinya masing-masing, antara lain untuk pengadaan barang dan jasa yang diperlukan. Pengadaan barang dan jasa dilakukan sesuai dengan prinsip-prinsip pengadaan yaitu efisien, efektif, transparan, terbuka, bersaing, adil, dan akuntabel. Tahap pertanggungjawaban dilakukan melalui kewajiban untuk menyusun Laporan Keuangan melekat pada Kuasa Pengguna Anggaran (KPA) dan menyerahkannya kepada pimpinan tertinggi sebagai bentuk pertanggungjawaban pelaksanaan tugasnya.

\subsection{SAKTI}

SAKTI merupakan aplikasi terintegrasi yang dikembangkan untuk dapat melakukan interkoneksi dengan Sistem Perbendahaan dan Anggaran Negara (SPAN) yang digunakan secara internal oleh Bendahara Umum Negara. Tujuan interkoneksi dengan sistem SPAN yang digunakan oleh Kantor Pelayanan Perbendaharaan Negara (KPPN) sebagai kuasa Bendahara Umum Negara di daerah adalah untuk memberikan kemudahan bagi Satker dengan mengurangi keharusan datang ke KPPN pada saat mengajukan tagihan pembayaran atas beban APBN. SAKTI digunakan oleh satuan kerja K/L untuk mengintegrasikan seluruh proses pengelolaan keuangan negara yang selama ini berjalan secara terpisah/parsial. SAKTI meliputi penggabungan fungsi-fungsi dalam penyusunan anggaran, pelaksanaan APBN, hingga penyusunan laporan keuangan. Pada penyusunan anggaran, fungsi yang akan digabung meliputi penyusunan RKA-KL, penyusunan DIPA, dan revisi DIPA. Pada pelaksanaan APBN, akan terdapat beberapa proses bisnis yang baru, yaitu manajemen data supplier, manajemen data kontrak, Resume Tagihan dan
Surat Perintah Membayar. Pada penyusunan laporan keuangan, penyempurnaan yang akan dilakukan meliputi aplikasi akuntansi keuangan, akuntansi barang milik negara, rekonsiliasi Sistem Akuntansi Instansi (SAI), penyusunan Laporan Pertanggungjawaban (LPJ) bendahara, dan akuntansi persediaan.

Pengiriman data dari Aplikasi SAKTI yang ada di lingkup satuan kerja ke Aplikasi SPAN yang ada pada Kementerian Keuangan dilakukan untuk memfasilitasi dan juga dikembangkan aplikasi pendukung yang meliputi Portal SPAN dan SPAN SMS. SAKTI adalah aplikasi yang digunakan untuk mendukung pelaksanaan sistem perbendaharaan dan penganggaran negara pada instansi pemerintah meliputi antara lain modul penganggaran, modul komitmen, modul pembayaran, modul bendahara, modul persediaan, modul aset tetap, modul piutang, serta modul akuntansi dan pelaporan.

Sejak awal tahun 2015, semua Kantor Pelayanan Perbendaharaan Negara (KPPN) telah menerapkan SPAN. Pada tahun 2017, seluruh satker lingkup Direktorat Jenderal Perbendaharaan sebagai target awal piloting telah menerapkan Aplikasi SAKTI. Peraturan teknis yang menjadi dasar penerapan Aplikasi SAKTI di Indonesia adalah sebagai berikut:

1. PMK Nomor 223/PMK.05/2015 tentang Pelaksanaan Piloting Sistem Aplikasi Keuangan Tingkat Instansi.

2. PMK Nomor 131/PMK.05/2016 tentang Perubahan Atas Peraturan Menteri Keuangan Nomor 223/PMK.05/2015 Tentang Pelaksanaan Piloting Sistem Aplikasi Keuangan Tingkat Instansi.

3. PMK Nomor 185/PMK. 05/2017 tentang Perubahan Kedua Atas Peraturan Menteri Keuangan Nomor 223/PMK.05/2015 Tentang Pelaksanaan Piloting Sistem Aplikasi Keuangan Tingkat Instansi.

4. PMK Nomor 159/PMK. 05/2018 tentang Pelaksanaan Piloting Sistem Aplikasi Keuangan Tingkat Instansi (PMK ini menghapus PMK sebelumnya). 
Adapun ruang lingkup SAKTI adalah sebagai berikut.

\section{Ruang lingkup aplikasi SAKTI}

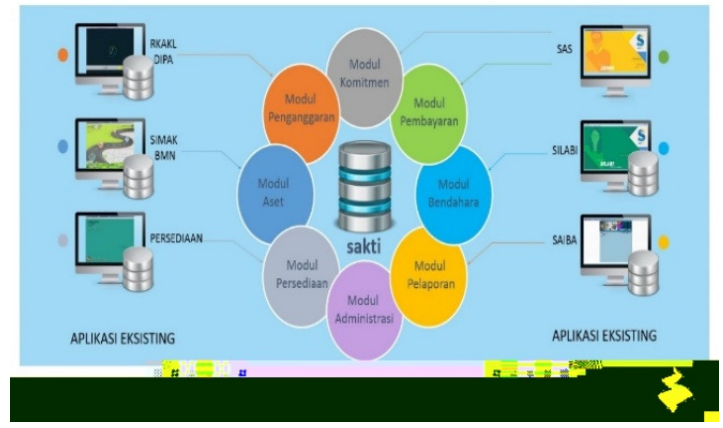

Gambar 1. Ruang Lingkup SAKTI

Sumber: Website DJPb

SAKTI merupakan aplikasi pendukung SPAN yang digunakan sebagai sarana bagi satker untuk melakukan pengelolaan keuangan dari tahapan perencanaan hingga pertanggungjawaban.

Berbagai modul yang ada di SAKTI:

1. Modul Penganggaran;

2. Modul Komitmen;

3. Modul Pembayaran;

4. Modul Bendahara;

5. Modul Persediaan;

6. Modul Aset Tetap;

7. Modul Akuntansi dan Pelaporan;

8. Modul Piutang;

9. Modul Administrator.

\subsection{PIECES Framework}

PIECES Framework adalah kerangka yang dipakai untuk mengklasifikasikan suatu problem, opportunities, dan directives yang terdapat pada bagian scope definition analisa dan perancangan sistem (Whitten \& Bentley, 2007, hal. 77), dikembangkan oleh James Wetherbe, sebagai alat untuk mengklasifikasikan masalah, peluang, dan kendala. Dengan kerangka ini, dapat dihasilkan halhal baru yang dapat menjadi pertimbangan dalam pengembangan sistem.

Analisis PIECES (Performance, Information, Economy, Control, Efficiency, dan Service) merupakan teknik untuk mengidentifikasi dan memecahkan permasalahan yang terjadi pada sistem informasi. Analisis ini akan menghasilkan identifikasi masalah utama dari suatu sistem serta memberikan solusi dari permasalahan tersebut, yang dirinci sebagai berikut;

a. P (Performance) : kinerja sistem, meliputi dimensi throughput dan waktu respon.

b. I (Information) : informasi yg disajikan, terdiri dari outputs, inputs, dan penyimpanan data.
c. E (Economics) : keuntungan yang dapat diraih (costs dan profits).
d. C (Control) : keamanan system.
e. E (Efficiency) : efisiensi orang dan proses.
f. S (Service) : layanan yang diberikan.

Analisis PIECES digunakan di banyak bidang, misalnya rumah sakit (Saragih, Lo, Reza, \& Setiyadi, 2013, hal. 16), perhotelan (Risanti, 2019, hal. 104), universitas (Ariawan, 2018, hal. 25), dan keuangan (Supriyatna, 2017, hal. 88). Melalui metode kepuasan layanan SAKTI, Mukhtaromin (2018, hal. 588) menyimpulkan satker BPPK secara keseluruhan, nilai kinerja faktor adalah 4,05 sehingga responden puas dengan kinerja SAKTI. Juga diidentifikasi faktor yang prioritas harus ditingkatkan sesuai dengan hasil IPA SAKTI adalah kelengkapan format laporan dalam aplikasi, kecepatan mempelajari aplikasi, kecepatan respon helpdesk atau service desk bila ada keluhan, kepastian kelebihan/kemanfaatan aplikasi SAKTI, dan kecepatan aplikasi dalam mendukung pembuatan laporan. Beberapa sistem informasi lain diteliti oleh Kristy \& Kusuma (2018, hal. 17), Supriyatna \& Maria (2017, hal. 88), Ramadhani \& Kusuma (2018, hal. 209) menyimpulkan tingkat kepuasan pengguna di atas 3,6 sedangkan tingkat kepentingan di atas 3,4.

\subsection{Kerangka Penelitian}

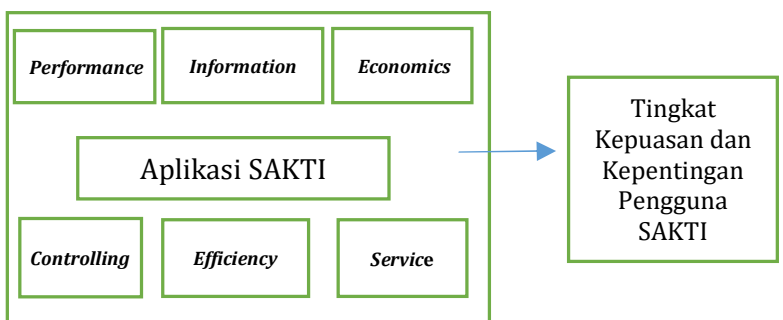

Gambar 2. Kerangka Pemikiran

Sumber: data diolah

\section{METODOLOGI PENELITIAN}

\subsection{Jenis Penelitian}

Jenis penelitian ini adalah penelitian deskriptif kuantitatif. Penelitian kuantitatif digunakan untuk meneliti pada populasi atau sampel tertentu, pengumpulan data menggunakan instrumen penelitian, adapun analisis data bersifat kuantitatif/statistik (Sugiyono, 2017, hal. 7), dilakukan dengan cara meneliti hubungan antar variabel yang diukur dengan instrumen penelitian (Creswell, 2016, hal. 5).

\subsection{Jenis dan Sumber Data}

Penelitian ini menggunakan data primer diperoleh dari hasil kuesioner kepada responden 
yaitu pengguna aplikasi SAKTI pada satker DJP. Di antara unit eselon I Kemenkeu di luar DJPb yang sudah menerapkan SAKTI terlebih dahulu, DJP memiliki satker terbanyak. Satker DJP di Jateng dan DIY mewakili satker DJP dengan alokasi anggaran besar dalam Daftar Isian Pelaksanaan Anggaran (DIPA) dan kegiatan yang beragam. Jumlah responden 45 orang yang berasal dari Kanwil DJP, Kantor Pelayanan Pajak (KPP) dan Kantor Pelayanan, Penyuluhan, dan Konsultasi Perpajakan (KP2KP) se-Jateng dan DIY. Selain itu juga dilakukan penelitian kepustakaan untuk menunjang penelitian ini.

Kuesioner digunakan untuk memperoleh informasi dari responden tentang tingkat kepentingan dan tingkat kepuasan pengguna SAKTI. Kuesioner ini terdiri beberapa pernyataan yang akan menjadi variabel dalam penelitian. Variabel tersebut yaitu Performance, Information, Economics, Control, Efficiency, dan Service.

Setiap variabel PIECES terdiri dari dua kategori yaitu tingkat kepuasan dan tingkat kepentingan. Setiap pertanyaan diukur dengan skala likert berupa jawaban sangat tidak penting sampai sangat penting dan sangat baik sampai sangat tidak baik. Jumlah pernyataan setiap item PIECES disesuaikan dengan penerapan aplikasi SAKTI.

Tabel 1. Jumlah Indikator per Variabel

\begin{tabular}{|l|l|c|}
\hline No & \multicolumn{1}{|c|}{ Variabel } & $\begin{array}{c}\text { Jumlah } \\
\text { Pernyataan }\end{array}$ \\
\hline 1 & Performance & 6 \\
\hline 2 & Information & 9 \\
\hline 3 & Economics & 3 \\
\hline 4 & Control & 6 \\
\hline 5 & Efficiency & 4 \\
\hline 6 & Service & 7 \\
\hline
\end{tabular}

Sumber : data diolah

\subsection{Metode Analisis Data}

Hasil kuesioner yang dikumpulkan kemudian dianalisis untuk mengetahui tingkat kepuasan dan kepentingan pengguna aplikasi SAKTI. Selanjutnya data dianalisis menggunakan analisis IPA. Data dikelompokkan pada kuadran kartesius yang menunjukkan tingkat kepuasan dan kepentingan.

Analisis kuantitatif menggunakan statistik deskriptif dan analisis IPA (Important Performance Analysis). Melalui IPA dapat diketahui pada bagian mana aplikasi SAKTI yang memerlukan perhatian lebih. Untuk mencerminkan hasil dan pembahasan yang dinyatakan dalam angka serta mendukung analisis tersebut digunakan Statistical Package for the Social Sciences (SPSS) untuk memudahkan perhitungan.

Metode Importance Performance Analysis (IPA) pertama kali diperkenalkan oleh Martilla \& James (1977, hal. 77) dengan tujuan untuk mengukur hubungan antara persepsi konsumen dan prioritas peningkatan kualitas produk/ jasa, dikenal juga dengan nama quadrant analysis. IPA digunakan untuk memetakan hubungan antara kepentingan dan kinerja masing-masing atribut yang ditawarkan dan kesenjangan antara kinerja dan harapan dari atribut tersebut. Matriks IPA terdiri dari sumbu $\mathrm{x}$ mewakili kepuasan dan sumbu $\mathrm{y}$ mewakili kepentingan. Maka akan didapat empat kuadran sebagai berikut.

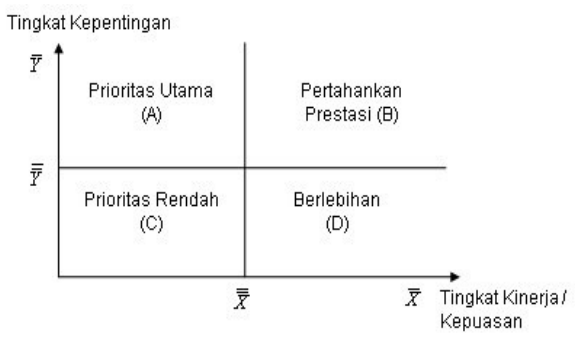

Gambar 3. Matriks IPA

Adapun interpretasi dari kuadran tersebuat adalah sebagai berikut:

\section{A. Prioritas Utama (Concentrate Here)}

Pada kuadran ini terdapat faktor-faktor yang dianggap penting dan atau diharapkan konsumen akan tetapi kinerja perusahaan dinilai belum memuaskan sehingga pihak perusahaan perlu berkonsentrasi untuk mengalokasikan sumber dayanya guna meningkatkan performa yang masuk pada kuadran ini.

\section{B. Pertahankan Prestasi (Keep Up The Good Work)}

Pada kuadran ini terdapat faktor-faktor yang dianggap penting dan diharapkan sebagai faktor penunjang kepuasan konsumen sehingga perusahaan wajib untuk mempertahankan prestasi kinerja tersebut.

\section{Prioritas Rendah (Low Priority)}

Pada kuadran ini terdapat faktor-faktor yang dianggap mempunyai tingkat persepsi atau kinerja aktual yang rendah dan tidak terlalu penting dan atau tidak terlalu diharapkan oleh konsumen sehingga perusahaan tidak perlu memprioritaskan atau memberikan perhatian lebih pada faktorfaktor tersebut.

\section{D.Berlebihan (Possibly Overkill)}

Pada kuadran ini terdapat faktor-faktor yang dianggap tidak terlalu penting dan tidak terlalu diharapkan oleh pelanggan sehingga perusahaan lebih baik mengalokasikan sumber daya yang terkait pada faktor tersebut kepada faktor lain yang lebih memiliki tingkat prioritas lebih tinggi. 


\section{HASIL PENELITIAN}

\subsection{Uji Validitas dan Reliabilitas Instrumen.}

Pengujian validitas alat ukur dilakukan dengan terlebih dahulu menghitung nilai korelasi dengan rumus Product Moment. Setelah dilakukan uji korelasi dengan menggunakan SPSS 25, didapatkan hasil nilai Pearson Correlation dari setiap variabel PIECES (6 variabel) untuk harapan/kepentingan dan persepsi/kenyataan. Semua butir pertanyaan tingkat kepentingan dan kepuasan untuk 6 variabel PIECES memiliki $r$ hitung> $r$ tabel, sehingga valid (ditandai dengan adanya tanda bintang dan signifikan pada taraf $0,05)$.

Reliabilitas suatu test merujuk pada derajat stabilitas, konsistensi, daya prediksi, dan akurasi. Pengukuran yang memiliki reliabilitas yang tinggi adalah pengukuran yang dapat menghasilkan data yang reliabel. Bila suatu alat pengukur dipakai dua kali untuk mengukur gejala yang sama dan hasil pengukuran yang diperoleh relatif konsisten, maka alat pengukur tersebut reliabel. Dengan kata lain, reliabilitas menunjukkan konsistensi suatu alat pengukur di dalam pengukur gejala yang sama. Uji reliabilitas pada penelitian ini menggunakan rumus Cronbach's Alpha.

Peneliti membuat uji reliabilitas dari setiap variabel PIECES (6 variabel) untuk harapan/ kepentingan dan persepsi/kenyataan. Sehingga terdapat 12 nilai uji.

\section{a. Reliabilitas Harapan/Kepentingan}

b. Reliabilitas Kenyataan/Persepsi

Setelah diuji dengan menggunakan SPSS 25 didapatkan hasil uji reliabilitas sebagaimana ditampilkan pada Tabel 2.

Tabel 2. Hasil uji reliabilitas kuesioner

\begin{tabular}{|l|l|l|l|}
\hline \multirow{2}{*}{$\begin{array}{l}\text { Variabel } \\
\text { PIECES }\end{array}$} & \multirow{2}{*}{$\begin{array}{l}\text { Jumlah } \\
\text { butir }\end{array}$} & \multicolumn{2}{|l|}{$\begin{array}{l}\text { Hasil uji } \\
\text { kuesioner }\end{array}$} \\
\cline { 3 - 4 } & & $\begin{array}{l}\text { Harapan/ } \\
\text { Kepentingan }\end{array}$ & $\begin{array}{l}\text { Kenyataan/ } \\
\text { Persepsi }\end{array}$ \\
\hline Performance & 6 & 0,885 & 0,922 \\
\hline Informasi & 9 & 0,861 & 0,913 \\
\hline Economics & 3 & 0,742 & 0,752 \\
\hline Control & 6 & 0,952 & 0,899 \\
\hline Efficiency & 4 & 0,945 & 0,860 \\
\hline Service & 7 & 0,847 & 0,908 \\
\hline
\end{tabular}

Sumber : data diolah

Dari uji validitas dan reliabilitas, didapatkan hasil bahwa 35 butir pertanyaan dalam kuesioner pengukuran tingkat kepuasan dan kepentingan, memiliki nilai alpha cronbach's ratarata diatas 0,8. Angka tersebut menunjukkan bahwa instrumen untuk mengukur variabel sudah valid dan reliabel sehingga dapat dipakai sebagai instrumen penelitian.

\subsection{Tingkat Kepuasan dan Kepentingan Pengguna}

Tingkat kepuasan dan tingkat kepuasan rata-rata pengguna aplikasi SAKTI, dianalisis dari penilaian responden berdasarkan skala likert, dengan persamaan berikut:

$$
R K=\frac{J S K}{J K}
$$

Dimana:

RK =rata-rata kepuasan/kepentingan

JSK = jumlah skor seluruh responden

$\mathrm{JK}=$ jumlah responden

Nilai kepuasan dan kepentingan, masingmasing dibagi kedalam 4 predikat yaitu, sangat puas, puas, tidak puas, sangat tidak puas (untuk persepsi/kenyataan), atau sangat penting, penting, tidak penting, dan sangat tidak penting (untuk kepentingan/harapan). Kategori predikat menggunakan interval berdasarkan rumus berikut:

$$
\begin{gathered}
\text { interval }=\frac{\text { nilai terting } \mathrm{i}-\text { nilai terendah }}{\text { jumlah predikat }} \\
=\frac{5-1}{4}=1
\end{gathered}
$$

Berdasarkan interval tersebut, maka kategori predikat adalah sebagai berikut (persepsi/ kepentingan):

$1-2,0$ : sangat tidak puas/sangat tidak penting)

$2,1-3,0$ : tidak puas/tidak penting

3,1-4,0: puas/penting

4,1 - 5,0 : sangat puas/sangat penting

Berdasarkan rumus tersebut diperoleh nilai rata-rata variabel PIECES sebagaimana ditunjukkan pada Tabel 3.

\begin{tabular}{|c|c|c|c|c|c|}
\hline \multirow[b]{2}{*}{$\begin{array}{c}\text { Domain } \\
\text { atribut }\end{array}$} & \multirow{2}{*}{$\begin{array}{l}\text { Kode } \\
\text { atribut }\end{array}$} & \multicolumn{2}{|c|}{ Tingkat Kepuasan } & \multicolumn{2}{|c|}{ Tingkat Kepentingan } \\
\hline & & $\begin{array}{l}\text { Rata- } \\
\text { rata }\end{array}$ & Predikat & $\begin{array}{l}\text { Rata- } \\
\text { rata }\end{array}$ & Predikat \\
\hline Performance & P1-P6 & 3,228 & Puas & 4,891 & $\begin{array}{l}\text { Sangat } \\
\text { Penting }\end{array}$ \\
\hline Information & I1 - I9 & 3,682 & Puas & 4,894 & $\begin{array}{l}\text { Sangat } \\
\text { Penting }\end{array}$ \\
\hline Economics & E1-E6 & 3,574 & Puas & 4,682 & $\begin{array}{l}\text { Sangat } \\
\text { Penting }\end{array}$ \\
\hline Control & C1- C6 & 3,764 & Puas & 4,875 & $\begin{array}{l}\text { Sangat } \\
\text { Penting }\end{array}$ \\
\hline Efficiency & Ef1-Ef4 & 3,401 & Puas & 4,883 & $\begin{array}{l}\text { Sangat } \\
\text { Penting }\end{array}$ \\
\hline Service & S1-S7 & 3,302 & Puas & 4,900 & $\begin{array}{l}\text { Sangat } \\
\text { Penting }\end{array}$ \\
\hline
\end{tabular}

Tabel 3. Nilai tingkat kepuasan dan tingkat kepentingan pengguna SAKTI Satker Kemenkeu

Sumber: data diolah

Dengan persamaan rata-rata kepuasan dan kepentingan untuk menentukan rata-rata tingkat kepentingan dan kepuasan pengguna terhadap 
penggunaan dan penerapan SAKTI diperoleh ratarata tingkat kepuasan berdasarkan domain yang terdapat pada PIECES framework adalah sebagai berikut (Tabel 5):

1) Tingkat Kepuasan

Berdasarkan hasil perhitungan jumlah ratarata tingkat kepuasan dengan menggunakan PIECES framework, maka didapatkan hasil bahwa pengguna SAKTI sudah merasa PUAS dalam penggunaan SAKTI. Diantara enam domain PIECES, semua poin mendapatkan nilai diatas 3,1 . Poin tertinggi terdapat pada poin control dengan nilai 3,764 kategori puas.

2) Tingkat Kepentingan

Berdasarkan hasil perhitungan jumlah ratarata tingkat kepentingan dengan menggunakan PIECES framework, maka didapatkan hasil bahwa penerapan SAKTI berdasarkan PIECES framework dianggap sangat penting untuk memudahkan pengguna SAKTI dalam melaksanakan pekerjaannya. Semua poin mendapatkan nilai diatas 4,1, sehingga masuk kategori sangat penting.

Berdasarkan hasil pengukuran tingkat kepuasan dan tingkat kepentingan atribut PIECES responden pengguna SAKTI, maka dihasilkan suatu perhitungan mengenai tingkat kesesuaian antara tingkat kepuasan dan tingkat kepentingan penggunaan dan penerapan SAKTI. Rumus yang digunakan untuk menghitung tingkat kesesuaian adalah sebagai berikut:

$$
T k i=\frac{X i}{Y i} \times 100 \%
$$

Di mana:

Tki = Tingkat kesesuaian responden.

$\mathrm{Xi}=$ Skor rata-rata tingkat kepuasan.

$\mathrm{Yi}=$ Skor rata-rata tingkat kepentingan.

Tingkat kesesuaian adalah hasil perbandingan skor tingkat kepuasan dengan tingkat kepentingan. Dalam analisis ini terdapat dua variabel yang diwakilkan dengan huruf $\mathrm{X}$ dan huruf $Y$, dimana huruf $X$ merupakan tingkat kepuasan sedangkan huruf $\mathrm{Y}$ adalah tingkat kepentingan. Tingkat kesesuaian antara tingkat kepuasan dan tingkat kepentingan secara rinci untuk setiap pernyataan pada variabel PIECES ditampilkan pada tabel berikut.

Tabel 4. Tingkat Kesesuaian antara Tingkat Kepuasan dan Tingkat Kepentingan

\begin{tabular}{|l|c|c|c|c|}
\hline Item & $\begin{array}{c}\text { Mean } \\
\text { Persepsi }\end{array}$ & $\begin{array}{c}\text { Mean } \\
\text { Harapan }\end{array}$ & Gap p -e & Tki (\%) \\
\hline P1 & 3,302325581 & 4,953488372 & $-1,65116279$ & 66,66667 \\
\hline P2 & 3,023255814 & 4,906976744 & $-1,88372093$ & 61,61137 \\
\hline P3 & 3,069767442 & 4,88372093 & $-1,81395349$ & 62,85714 \\
\hline P4 & 3,465116279 & 4,837209302 & $-1,37209302$ & 71,63462 \\
\hline P5 & 3,23255814 & 4,860465116 & $-1,62790698$ & 66,50718 \\
\hline P6 & 3,279069767 & 4,906976744 & $-1,62790698$ & 66,82464 \\
\hline
\end{tabular}

\begin{tabular}{|c|c|c|c|c|}
\hline I1 & 3,76744186 & 4,930232558 & $-1,1627907$ & 76,41509 \\
\hline 12 & 3,558139535 & 4,790697674 & $-1,23255814$ & 74,27184 \\
\hline I3 & 3,534883721 & 4,906976744 & $-1,37209302$ & 72,03791 \\
\hline I4 & 3,674418605 & 4,930232558 & $-1,25581395$ & 74,5283 \\
\hline I5 & 3,627906977 & 4,88372093 & $-1,25581395$ & 74,28571 \\
\hline I6 & 3,790697674 & 4,837209302 & $-1,04651163$ & 78,36538 \\
\hline I7 & 3,904761905 & 4,860465116 & $-0,95570321$ & 80,33721 \\
\hline 18 & 3,488372093 & 4,953488372 & $-1,46511628$ & 70,42254 \\
\hline 19 & 3,813953488 & 4,953488372 & $-1,13953488$ & 76,99531 \\
\hline E1 & 3,488372093 & 4,76744186 & $-1,27906977$ & 73,17073 \\
\hline E2 & 3,604651163 & 4,488372093 & $-0,88372093$ & 80,31088 \\
\hline E3 & 3,627906977 & 4,790697674 & $-1,1627907$ & 75,72816 \\
\hline C1 & 3,697674419 & 4,88372093 & $-1,18604651$ & 75,71429 \\
\hline C2 & 3,813953488 & 4,860465116 & $-1,04651163$ & 78,4689 \\
\hline C3 & 3,813953488 & 4,88372093 & $-1,06976744$ & 78,09524 \\
\hline C4 & 3,604651163 & 4,88372093 & $-1,27906977$ & 73,80952 \\
\hline C5 & 3,88372093 & 4,88372093 & -1 & 79,52381 \\
\hline C6 & 3,76744186 & 4,860465116 & $-1,09302326$ & 77,51196 \\
\hline Ef1 & 3,441860465 & 4,88372093 & $-1,44186047$ & 70,47619 \\
\hline Ef2 & 3,23255814 & 4,88372093 & $-1,65116279$ & 66,19048 \\
\hline Ef3 & 3,627906977 & 4,88372093 & $-1,25581395$ & $\mathbf{7 4 , 2 8 5 7 1}$ \\
\hline Ef4 & 3,302325581 & 4,880952381 & $-1,5786268$ & 67,6574 \\
\hline S1 & 3,790697674 & 4,953488372 & $-1,1627907$ & 76,52582 \\
\hline S2 & 3,348837209 & 4,930232558 & $-1,58139535$ & 67,92453 \\
\hline S3 & 3,302325581 & 4,953488372 & $-1,65116279$ & 66,66667 \\
\hline 54 & 3 & 4,930232558 & $-1,93023256$ & 60,84906 \\
\hline S5 & 3,023255814 & 4,88372093 & $-1,86046512$ & 61,90476 \\
\hline S6 & 3,441860465 & 4,860465116 & $-1,41860465$ & 70,8134 \\
\hline S7 & 3,209302326 & 4,790697674 & $-1,58139535$ & 66,99029 \\
\hline Jumlah & 122,5559247 & 170,5321152 & $-47,9761905$ & 2516,379 \\
\hline C Line & 3,501597848 & 4,872346148 & $-1,3707483$ & 71,89653 \\
\hline
\end{tabular}

Sumber : data diolah

Berdasarkan tabel 4, dapat diketahui bahwa semua pernyataan memiliki nilai gap yang negatif. Kinerja seluruh atribut belum memenuhi harapan dari stakeholder. Responden menilai bahwa kepuasan kinerja ada di bawah kepentingan mereka dengan nilai gap yang bervariasi.

Gap yang paling rendah yaitu $-0,8837209$ pada atribut kode E2 (pada saat pembangunan dan penerapan SAKTI, biaya yang dikeluarkan DJPb cukup tinggi). Gap yang paling tinggi berada pada butir pertanyaan kode S4 dengan nilai gap yang sama yaitu -1,9302326. Responden menyatakan bahwa SAKTI belum memenuhi harapan mereka terkait kinerja atribut "SAKTI fleksibel jika digunakan untuk situasi yang baru". 
Jika dilihat pada setiap variabelnya secara umum, berikut gap antara kepuasan dan kepentingan setiap variabel PIECES.

Tabel 5. Gap Tingkat Kepuasan dan Tingkat Kepentingan

\begin{tabular}{|l|l|l|l|l|}
\hline \multicolumn{1}{|c|}{ Variabel } & \multicolumn{1}{c|}{$\begin{array}{c}\text { Mean } \\
\text { Kepuasan }\end{array}$} & $\begin{array}{c}\text { Mean } \\
\text { Kepentingan }\end{array}$ & Gap & Tki (\%) \\
\hline Performance & 3,228682 & 4,891473 & $-1,66279$ & 66,00634 \\
\hline Information & 3,684508 & 4,894057 & $-1,20955$ & 75,28536 \\
\hline Economics & 3,573643 & 4,682171 & $-1,10853$ & 76,3245 \\
\hline Control & 3,763566 & 4,875969 & $-1,1124$ & 77,18601 \\
\hline Efficiency & 3,401163 & 4,883029 & $-1,48187$ & 69,65273 \\
\hline Service & 3,302326 & 4,900332 & $-1,59801$ & 67,38983 \\
\hline
\end{tabular}

Sumber : data diolah

Dari tabel nilai rata-rata tingkat kepuasan dan kepentingan di atas (tabel 5), diperoleh tingkat kesesuaian enam domain kerangka PIECES antara tingkat kepuasan pengguna dengan tingkat kepentingan penerapan SAKTI, yaitu sebagai berikut:

a. Tingkat kesesuaian domain performance sebesar $66,00 \%$ yang berarti persepsi pengguna terhadap kepuasan lebih kecil dibandingkan kepentingan;

b. Tingkat kesesuaian domain information sebesar $75,28 \%$ yang berarti persepsi pengguna terhadap kepuasan lebih kecil dibandingkan kepentingan;

c. Tingkat kesesuaian domain economics sebesar $76,32 \%$ yang berarti persepsi pengguna terhadap kepuasan lebih kecil dibandingkan kepentingan;

d. Tingkat kesesuaian domain control sebesar 77,19\% yang berarti persepsi pengguna terhadap kepuasan lebih kecil dibandingkan kepentingan;

e. Tingkat kesesuaian domain efficiency sebesar $69,65 \%$, yang berarti persepsi pengguna terhadap kepuasan lebih kecil dibandingkan kepentingan.

f. Sedangkan tingkat kesesuaian domain service sebesar 67,39\%, yang berarti persepsi pengguna terhadap kepuasan lebih kecil dibandingkan kepentingan.

Secara rata-rata pengguna menganggap bahwa harapan mereka terhadap aplikasi SAKTI masih belum terpenuhi. Nilai rata-rata sebesar 71,97\% berarti persepsi pengguna terhadap kepuasan lebih kecil dibandingkan kepentingan.

\subsection{Analisis IPA Tingkat Kepuasan dan Kepentingan Pengguna}

Dari data tabel 4 maka perlu analisis lebih lanjut untuk menentukan skala prioritas dalam usaha perbaikan dari setiap atribut yang ada. Adapun cara untuk menentukan skala prioritas pembenahan adalah dengan menggunakan metode Importance Performance Analysis (IPA). Metode yang digunakan adalah deskriptif kuantitatif. Metode IPA mengukur tingkat kepuasan dan harapan pengguna SAKTI dan dipetakan pada kuadran-kuadran importance performance matrix, menggunakan diagram kartesius.

Diagram kartesius merupakan suatu bangun yang dibagi atas empat bagian yang dibatasi oleh dua buah garis yang berpotongan tegak lurus pada titik rata-rata skor tingkat kepuasan/persepsi/kenyataan dan rata-rata tingkat kepentingan/harapan. Sumbu mendatar (X) diisi oleh skor tingkat kepuasan, sedangkan sumbu tegak (Y) diisi oleh skor tingkat kepentingan. Berdasarkan data rata-rata X (Kepuasan) dan Y (Kepentingan), keseluruhan atribut PIECES dapat dipetakan pada Gambar 4.

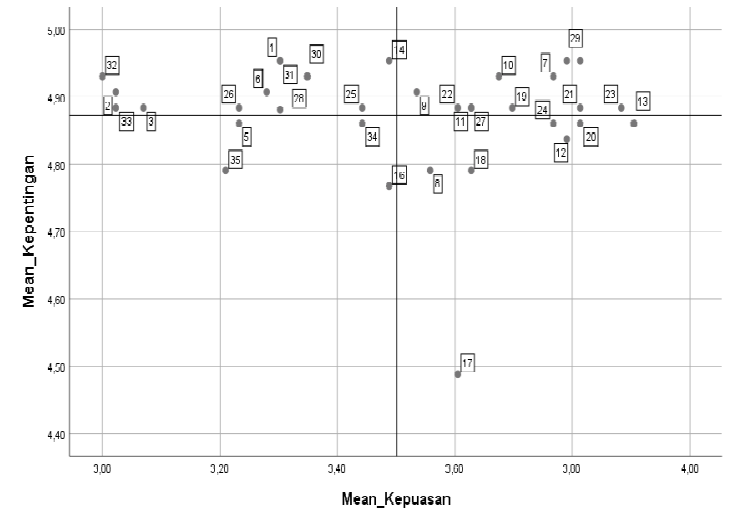

Gambar 4. Diagram Kartesius SAKTI

Interpretasi dari diagram kartesius seperti pada Gambar 4 dapat dijelaskan sebagai berikut:

a. Kuadran A.

Kuadran ini menunjukkan faktor yang memengaruhi kepuasan pengguna dan kepentingan penerapan SAKTI yang perlu diprioritaskan untuk ditingkatkan kinerjanya. Komponen yang berada pada kuadran ini adalah sebagai berikut.

Tabel 6. Atribut PIECES Kuadran A

\begin{tabular}{|l|l|}
\hline Butir & Uraian \\
\hline & Performance \\
\hline P1 & SAKTI mudah diakses oleh pengguna. \\
\hline P2 & $\begin{array}{l}\text { SAKTI dapat mengoperasikan sejumlah } \\
\text { perintah dalam waktu yang relatif singkat, } \\
\text { tanpa mengalami hambatan. }\end{array}$ \\
\hline P3 & $\begin{array}{l}\text { SAKTI dalam merespons suatu perintah } \\
\text { pembatalan maupun permintaan terhadap } \\
\text { suatu transaksi dilakukan dengan cepat. }\end{array}$ \\
\hline
\end{tabular}




\begin{tabular}{|c|c|}
\hline P6 & $\begin{array}{l}\text { Total waktu yang dibutuhkan dalam } \\
\text { melakukan pengolahan data hingga } \\
\text { menghasilkan informasi sudah dilakukan } \\
\text { dengan cepat. }\end{array}$ \\
\hline & Information \\
\hline \multirow[t]{2}{*}{ I8 } & $\begin{array}{l}\text { Informasi yang disajikan SAKTI mudah } \\
\text { untuk dipelajari dan dipahami. }\end{array}$ \\
\hline & Efficiency \\
\hline Ef1 & $\begin{array}{l}\text { Dalam pemeliharaan sistem, tidak } \\
\text { mengalami kesulitan baik dari segi biaya } \\
\text { maupun pelaksanaannya. }\end{array}$ \\
\hline Ef2 & $\begin{array}{l}\text { Sistem yang digunakan sekarang lebih } \\
\text { meringankan pengguna baik dari segi biaya } \\
\text { dan waktu. }\end{array}$ \\
\hline \multirow[t]{2}{*}{ Ef4 } & $\begin{array}{l}\text { Dalam mengoperasikan sistem pada } \\
\text { kegiatan/aktivitas sehari-hari, sistem } \\
\text { dapat menghasilkan output yang sesuai } \\
\text { dengan waktu dan material yang minimal. }\end{array}$ \\
\hline & Service \\
\hline S2 & SAKTI mudah dipelajari dan dipahami. \\
\hline S3 & SAKTI mudah digunakan. \\
\hline $\mathrm{S} 4$ & $\begin{array}{l}\text { SAKTI fleksibel jika digunakan untuk } \\
\text { situasi yang baru. }\end{array}$ \\
\hline S5 & ara fleksibel. \\
\hline
\end{tabular}

Sumber: data diolah

Terdapat 12 pernyataan yang berada di kuadran A. Responden menganggap bahwa performance dan service sebuah aplikasi sangat menentukan tingkat kepuasan pengguna. Beberapa kondisi yang dihadapi responden yang menimbulkan ketidakpuasan misalnya saat melakukan revisi pada modul penganggaran. Waktu yang dibutuhkan untuk pengolahan data lama, data detil bergeser. Perekaman kuitansi yang memunculkan persediaan pada modul bendahara juga menimbulkan ketidakpuasan. Nantinya akan juga mempengaruhi LPJ Bendahara. Modul persediaan belum bisa digunakan di SAKTI.

\section{b. Kuadran B.}

Kuadran ini menunjukkan bahwa faktor yang mempengaruhi kepuasan pengguna dan kepentingan penerapan SAKTI, termasuk ke dalam kategori yang sudah baik dan harus dipertahankan.
Tabel 7. Atribut PIECES Kuadran B

\begin{tabular}{|l|l|}
\hline Butir & Uraian \\
\hline I1 & $\begin{array}{l}\text { Data yang disimpan oleh SAKTI sudah } \\
\text { tersimpan sesuai dengan yang dimasukkan } \\
\text { ke dalam sistem. }\end{array}$ \\
\hline I3 & $\begin{array}{l}\text { Sistem informasi SAKTI tidak dapat } \\
\text { menyimpan data yang sama sehingga tidak } \\
\text { menimbulkan duplikasi atau redudansi } \\
\text { data. }\end{array}$ \\
\hline I4 & $\begin{array}{l}\text { Informasi yang dihasilkan oleh SAKTI } \\
\text { sudah sesuai dengan yang dibutuhkan. }\end{array}$ \\
\hline I5 & $\begin{array}{l}\text { Informasi yang dihasilkan oleh SAKTI tepat } \\
\text { pada waktunya. }\end{array}$ \\
\hline I9 & $\begin{array}{l}\text { Informasi yang dihasilkan SAKTI dapat } \\
\text { diandalkan/dipercaya. }\end{array}$ \\
\hline Ef \\
Control \\
\hline Pengguna dalam penggunaan SAKTI. \\
\hline C1
\end{tabular}

Sumber: data diolah

Terdapat sebelas atribut yang berada di kuadran B. Atribut yang terdapat di kuadran ini harus dipertahankan. Hal ini tergali dari wawancara kepada responden yaitu pada atribut service. Pihak DJPb memberikan bantuan kepada pengguna dalam penggunaan SAKTI. Selama ini konsultasi mengenai SAKTI lebih banyak diarahkan ke KPPN. Selain itu juga dilakukan bimbingan teknis dari KPPN kepada satker, walaupun lebih banyak mengunakan video conference. Satker mengusulkan agar bimbingan teknis/pelatihannya dilakukan per modul SAKTI. 
c. Kuadran C.

Kuadran ini menunjukkan faktor yang mempengaruhi kepuasan pengguna dan kepentingan penerapan SAKTI, termasuk ke dalam kategori prioritas rendah. Hal ini menggambarkan bahwa butir-butir PIECES pada kuadran ini tidak terlalu penting.

Tabel 8. Atribut PIECES Kuadran C

\begin{tabular}{|l|l|}
\hline Butir & Uraian \\
\hline P5 & $\begin{array}{l}\text { Performance } \\
\text { bersamaan, kinerja sistem informasi tetap } \\
\text { berjalan stabil. }\end{array}$ \\
\hline Efficiency \\
\hline Biaya yang dikeluarkan menjadi lebih \\
ringan dengan adanya SAKTI \\
dibandingkan dengan menggunakan cara \\
konvensional.
\end{tabular}

Sumber: data diolah

Jumlah atribut yang berada di kuadran C adalah empat atribut dengan kategori prioritas rendah. Terdapat usulan terkait Kartu Kredit Pemerintah (KKP), usulan agar DJPb aktif jika terdapat update pada aplikasi SAKTI.

\section{d. Kuadran D}

Kuadran ini menunjukkan bahwa faktor yang memengaruhi kepuasan pengguna dan kepentingan penerapan SAKTI, masuk dalam kategori berlebihan.

Tabel 9. Atribut PIECES Kuadran D

\begin{tabular}{|l|l|}
\hline Butir & Uraian \\
\hline P4 & $\begin{array}{l}\text { Jumlah data yang dapat diproses SAKTI } \\
\text { pada satuan waktu sudah sesuai dengan } \\
\text { yang diharapkan. }\end{array}$ \\
\hline Information \\
\hline I6 & $\begin{array}{l}\text { Data yang mengandung kesalahan atau } \\
\text { data yang tidak benar tidak dapat } \\
\text { disimpan oleh SAKTI. }\end{array}$ \\
\hline $\begin{array}{l}\text { Format informasi yang dihasilkan oleh } \\
\text { SAKTI bermanfaat dan dapat digunakan } \\
\text { sebagaimana mestinya oleh pengguna. }\end{array}$ \\
\hline
\end{tabular}

\begin{tabular}{|l|l|}
\hline I7 & $\begin{array}{l}\text { Data yang diolah oleh SAKTI sudah } \\
\text { tersimpan ke dalam satu media } \\
\text { penyimpanan. } \\
\text { Economics }\end{array}$ \\
\hline E2 & $\begin{array}{l}\text { Pada saat pembangunan dan penerapan } \\
\text { SAKTI, biaya yang dikeluarkan DJPb } \\
\text { cukup tinggi. }\end{array}$ \\
\hline E3 & $\begin{array}{l}\text { Ada perubahan yang signifikan dalam hal } \\
\text { perkembangan dan pertumbuhan dengan } \\
\text { adanya SAKTI }\end{array}$ \\
\hline C2 & $\begin{array}{l}\text { Tentrol } \\
\text { terhadap penggunaan data. }\end{array}$ \\
\hline C6 & $\begin{array}{l}\text { Media pengontrolan terpusat } \\
\text { mengorganisasikan data dengan baik. }\end{array}$ \\
\hline
\end{tabular}

Sumber: data diolah

Terdapat delapan atribut yang berada pada kuadran D. Atribut yang berada di kuadran ini menunjukkan kategori berlebihan. Walaupun kategori berlebihan, responden merasakan aplikasi SAKTI banyak manfatnya untuk membantu pekerjaan sehari-hari.

\section{KESIMPULAN DAN SARAN}

\subsection{Kesimpulan}

Berdasarkan hasil analisis data, maka dapat disimpulkan sebagai berikut.

1. Berdasarkan PIECES Framework, yang terdiri dari Performance, Information, Economics, Control, Efficiency, dan Service untuk mengukur tingkat kepuasan dan kepentingan pengguna sistem informasi SAKTI, didapatkan hasil sebagai berikut:

a. Pengguna merasa puas dengan aplikasi SAKTI. Domain control mendapat nilai paling tinggi untuk kepuasan yaitu 3,764 dan domain performance mendapat nilai paling rendah namun tetap pada kategori puas yaitu 3,228. Secara umum SAKTI memiliki keunggulan, namun tetap diperlukan adanya perbaikan dan pengembangan untuk menutupi kelemahan yang ada.

b. Jika dibandingkan antara nilai kepuasan dan kepentingan pengguna SAKTI, maka nilai kepuasan lebih rendah dibandingkan kepentingannya. Gap antara kepuasan dan kepentingan memiliki nilai negatif, artinya pengguna memiliki harapan yang lebih besar dibandingkan dengan kenyataan yang dihadapi. Tingkat kepentingan yang paling tinggi adalah domain service yaitu 4,900 dan terendah adalah 4,682 pada domain economics. Atribut terbaik yang ada pada SAKTI adalah atribut economics sedangkan 
item yang perlu mendapat perhatian lebih adalah atribut performance.

2. Analisis IPA menunjukan bahwa sebagian besar atribut, yaitu 12 atribut berada di kuadran A yaitu perlu diprioritaskan untuk ditingkatkan kinerjanya. Sedangkan 11 atribut berada di kuadran B yaitu termasuk ke dalam kategori yang sudah baik dan harus dipertahankan. Sebanyak 4 atribut berada di kuadran $C$ yaitu kategori prioritas rendah dan 8 atribut berada di kuadran D yaitu masuk dalam kategori berlebihan. Unsur performance dan service banyak berada di kuadran A. Faktor ini yang harus mendapat perhatian untuk ditingkatkan agar kepuasan pengguna semakin meningkat.

\subsection{Saran}

Berkaitan dengan hasil analisis dan kesimpulan, maka diberikan saran sebagai berikut.

a. Kepada pengembang aplikasi agar meningkatkan kinerja SAKTI terutama pada item yang masuk di kuadran A. Hal ini dengan tujuan untuk meningkatkan kepuasan pengguna SAKTI.

b. Perlunya pendataan dan identifikasi permasalahan yang terjadi pada satker oleh KPPN dan Kanwil DJPb untuk mendapatkan langkah strategis/teknis berikutnya.

c. Perlunya dilakukan sosialisasi dan bimbingan teknis secara sistematis kepada pengguna SAKTI terutama jika terdapat update terhadap aplikasi. Dengan kemajuan TIK yang semakin pesat, maka dapat memanfaatkan media sosial untuk keperluan tersebut.

d. Manual aplikasi SAKTI yang mudah digunakan oleh pengguna perlu dibuat untuk lebih mendekatkan pengembang aplikasi dan pengguna. Hal ini juga dapat meminimalisir munculnya pertanyaan berulang dari satker.

e. Dalam jangka panjang dapat dipikirkan untuk penggunaan SAKTI mobile sehingga pengguna lebih fleksibel dalam memanfaatkan aplikasi.

\section{IMPLIKASI DAN KETERBATASAN \\ 6.1. Implikasi Penelitian}

Implikasi penelitian ini dari aspek praktis diharapkan dapat memberikan manfaat bagi Kementerian Keuangan c.q. Direktorat Jenderal Perbendaharaan sebagai pengembang dan host aplikasi SAKTI mengenai perlunya evaluasi untuk pengembangan aplikasi SAKTI. Penelitian ini juga berimplikasi pada analisis kebijakan pengembangan dan penyempurnaan SAKTI ke depan terutama untuk go live SAKTI kepada semua satker Kementerian/Lembaga.

\subsection{Keterbatasan}

1. Penelitian ini terbatas pada ruang lingkup responden pengguna SAKTI pada DJP Wilayah Jateng dan DIY. Jika penelitian ini dilakukan di satuan kerja yang lain, bisa jadi akan mendapatkan hasil yang berbeda.

2. Data yang digunakan dalam penelitian ini adalah data kuantitatif dari kuesioner yang dibagikan kepada responden, sehingga peneliti mengesampingkan adanya data lain yang kemungkinan ada.

3. Peneliti belum menggali lebih jauh tingkat kepuasan pengguna SAKTI menggunakan kerangka/model lain, maka perlu penelitian lanjutan untuk mengetahui hasil berbeda pada pendekatan berbeda.

\section{REFERENSI}

Ariawan, P. A., Putra, I. S., \& Mertasana, P. A. (2018). Design and analysis of mail management information system using pieces method: a case study at faculty of mathematics and natural sciences of Udayana University. International Journal of Engineering and Emerging Technology, [S.l.], 2(2), 25-30.

Creswell, J. W. (2016). Research design: pendekatan metode kualitatif, kuantitatif, dan campuran. Edisi 4. Yogyakarta: Pustaka Pelajar.

DeLone, W. H., \& McLean, E. R. (1992). Information systems success: the quest for the dependent variable. Information Systems Research, The Inslilulc of Management Stienees, 3(1), 60-95.

Iswardani, P. R., Pramana, I. W. S., \& Sudarmodjo, Y. P. (2019). Design of hotel warehouse management information system based on pieces analysis. International Journal of Engineering and Emerging Technology, [S.l.],3(2), 104-108.

KPPN Metro. (2019). Overview SAKTI. Diakses tanggal 19 November 2019, dari http://www.djpbn.kemenkeu.go.id/kppn/metro/i d/sakti/overview-sakti/modul-modul-sakti.html.

Kristy, R. D., \& Kusuma, W. A. (2018). Analisis tingkat kepuasan dan tingkat kepentingan penerapan sistem informasi Universitas Muhammadiyah Malang. Teknik: Engineering and Sains Journal, 2(1), 17-24.

Martilla, J. A., \& James, J. C. (1997). Importanceperformance analysis. Journal of Marketing, 41(1), 77-79.

Mukhtaromin. (2018). Kepuasan pengguna sistem aplikasi keuangan tingkat instansi (sakti) pada badan pendidikan dan pelatihan keuangan (bppk). Prosiding SNKN BPPK. 2018, 588-602. 
104

Peraturan Menteri Keuangan Nomor 159/PMK.05/2018 tentang Pelaksanaan Piloting Sistem Aplikasi Keuangan Tingkat Instansi.

Peraturan Menteri Keuangan Nomor 223/PMK.05/2015 tentang Pelaksanaan Piloting Sistem Aplikasi Keuangan Tingkat Instansi.

Peraturan Menteri Keuangan Nomor 131/PMK.05/2016 tentang Perubahan Atas Peraturan Menteri Keuangan Nomor 223/PMK.05/2015 Tentang Pelaksanaan Piloting Sistem Aplikasi Keuangan Tingkat Instansi.

Peraturan Menteri Keuangan Nomor 185/PMK.05/2017 tentang Perubahan Kedua Atas Peraturan Menteri Keuangan Nomor 223/PMK.05/2015 Tentang Pelaksanaan Piloting Sistem Aplikasi Keuangan Tingkat Instansi.

Peraturan Menteri Keuangan Nomor 159/PMK.05/2018 tentang Pelaksanaan Piloting Sistem Aplikasi Keuangan Tingkat Instansi.

Ramadhani, S., \& Kusuma, W. A. (2018). PIECES framework untuk analisa tingkat kepuasan pengguna dan kepentingan sistem informasi. Jurnal
Teknologi \& Manajemen Informatika, 4(2), 209214.

Saragih, H., Lo, L., Reza, B., \& Setiyadi, D. (2013). Analysis information system of inpatient billing system's support for consumables logistics using pieces framework: case study promedika hospital. Jurnal Sistem Informasi, 8(1), 16-21.

Simarmata, J. (2006). Pengenalan Teknologi Komputer dan Informasi. Yogyakarta: Penerbit Andi.

Sugiyono. (2017). Metode penelitian kuantitatif, kualitatif, dan r\&d. Bandung: Penerbit Alfabeta.

Supriyatna, A., \& Maria, V. (2017). Analisis tingkat kepuasan pengguna dan tingkat kepentingan penerapan sistem informasi djp online dengan kerangka pieces. Khazanah Informatika, 3(2), 8894.

Suyanto. (2005). Teknologi informasi untuk bisnis. Yogyakarta: Penerbit Andi.

Whitten, J. L., \& Bentley, L. D. (2007). System analysis and design methods seventh edition. New York:

McGraw 